\title{
Mediações na comunicação hospitalar em uma Região de Saúde do Rio Grande do Sul
}

\author{
Lidia Schwantes Hoss \\ Universidade de Santa Cruz do Sul (Unisc) \\ Angela Cristina Trevisan Felippi \\ Universidade de Santa Cruz do Sul (Unisc)
}

Recebido: 10/05/2017 Versão revisada (entregue): 13/04/2018 Aprovado: 17/06/2018

\begin{abstract}
Resumo
Nesse artigo se analisa o processo de produção da comunicação hospitalar numa Região de Saúde do Estado do Rio Grande do Sul, com o objetivo de conhecer a concepção que orienta as práticas de comunicação externa dos hospitais, com vistas a compreender, a partir da produção comunicacional, como a política pública de saúde se materializa nos territórios. Aqui, a comunicação dentro da cultura é compreendida como um processo e, assim, sensível a mediações. A partir do mapa das mediações de Jesús Martín-Barbero, foram estudados os momentos das "lógicas de produção" e dos "produtos industriais" com observância das mediações da "institucionalidade" e da "tecnicidade". A pesquisa tem natureza qualitativa e valeu-se dos estudos culturais, da teoria das mediações, dos estudos de comunicação pública e de território como referenciais teóricos. Questionário, entrevistas, pesquisa bibliográfica e documental foram os instrumentos utilizados. A partir da análise verificou-se a dualidade entre as práticas comunicacionais hospitalares, oscilando entre uma comunicação de caráter efetivamente público e outra, com ênfase à divulgação e venda de serviços privados de saúde, indicando que política de saúde pública se concretiza nos territórios a partir de suas particularidades.
\end{abstract}

Palavras-chave | Comunicação pública; hospital; mediação; Região de Saúde; Rio Grande do Sul; território.

Código JEL |I13; I18; R12.

\section{HOSPITAL COMMUNICATION MEDIATION ON A HEALTH REGION IN RIO GRANDE DO SUL}

\section{Abstract}

This article analyzes the process of hospital communication on a Health Region in the State of Rio Grande do Sul, Brazil. It is to know the concept that guides the practices of external communication of hospitals with a view to understanding, from the communicational, how the public health policy materializes in the territories. Here, communication, within culture, is understood as a process and thus, sensitive to mediations. From the map of the mediations of Jesús Martín-Barbero, the moments of "production logics" and "industrial products" were 
studied, observing the mediations of "institutionality" and "technicity". The research has a qualitative nature and was based on the theory of cultural studies, the theory of mediations, the studies of public communication and territory as theoretical references. Questionnaire, interviews, bibliographic and documentary research were the instruments used. From the analysis, was verified the duality between hospital communication practices, oscillating between a communication of an effective public nature and another, with emphasis on the dissemination and sale of private health services, indicating that public health policy is implemented in the territories from of its particularities.

Keywords | Health Region; hospital; mediation; public communication; Rio Grande do Sul; territory.

JEL-Code |I13; I18; R12.

\section{MEDIACIONES EN LA COMUNICACIÓN HOSPITALARIA EN UNA REGIÓN DE SALUD DE RIO GRANDE DO SUL}

\section{Resumen}

En este artículo se analiza el proceso de producción de la comunicación hospitalaria en una Región de Salud del Estado de Rio Grande do Sul, con el objetivo de conocer la concepción que orienta las prácticas de comunicación externa de los hospitales, con vista a comprender, a partir de la producción comunicacional, cómo la política pública de salud se materializa en los territorios. Aquí, la comunicación dentro de la cultura es comprendida como un proceso y, así, sensible a mediaciones. A partir del mapa de las mediaciones de Jesús Martín-Barbero, fueron estudiados los momentos de las "lógicas de producción" y de los "productos industriales" observando las mediaciones de la "institucionalidad" y de la "tecnicidad". La investigación tiene una naturaleza cualitativa y se valió de los estudios culturales, de la teoría de las mediaciones, de los estudios de comunicación pública y de territorio como referenciales teóricos. Cuestionarios, entrevistas, investigación bibliográfica y documental fueron los instrumentos utilizados. A partir del análisis se verificó la dualidad entre las prácticas comunicacionales hospitalarias, oscilando entre una comunicación de carácter efectivamente público y otra, con énfasis en la divulgación y venta de servicios privados de salud, indicando que la política de salud pública se concreta en los territorios a partir de sus particularidades.

Palabras-clave | comunicación pública; hospital; mediación; Región de Salud; Rio Grande do Sul; territorio.

Código JEL |I13; I18; R12.

\section{Introdução}

Como contexto principal deste estudo coloca-se a comunicação dos hospitais com a sociedade brasileira, sua articulação com o setor da saúde e a região. O campo profissional da Comunicação na interseção com o Desenvolvimento Regional expõe toda a complexidade inerente a essa interação que envolve as práticas culturais e sociais e sua articulação em contato com a dinâmica espacial dos territórios. Como já dito em textos anteriores, “a comunicação transita pelo 
desenvolvimento regional, expressando trajetórias, processos e articulações entre cultura e comunicação construídas no cotidiano de uma sociedade que se globaliza, evidenciando as diversas formas de expressar o tempo e o espaço" (FELIPPI e BRAND'T 2016, p.60).

As práticas comunicacionais dos hospitais podem, entre vários aspectos, colaborar para o ambiente de desenvolvimento regional por meio da divulgação de informações de saúde de interesse público. As questões voltadas à saúde despertam a atenção da sociedade e os hospitais, como um dos principais agentes de saúde, estão no centro das atenções e pressões de demandas públicas e privadas. O modelo de saúde brasileiro persiste "hospitalocêntrico", sendo caracterizado pela centralização do sistema na figura do médico e do hospital em detrimento do "redebásicocêntrico", com foco na rede básica, conforme Carvalho, Freire e Vilar (2012) e López (2004). Dessa forma, a relação comunicação e saúde tem ligação intrínseca com o desenvolvimento das regiões e pode interferir positivamente ou não no acesso a políticas e serviços de saúde pública, bem como no debate sobre o lugar dos hospitais no sistema de saúde do país.

O hospital é um espaço onde interagem as instâncias governamentais, planos de saúde privados, entidades da sociedade civil, profissionais de saúde e pacientes. Neste ambiente, a comunicação se coloca como uma ferramenta estratégica para pensar e conduzir a gestão dos hospitais com seus diversos interlocutores e, sobretudo, para dar a conhecer à sociedade os serviços a que tem direito. Comunicar-se de forma clara, transparente e ágil com os diversos públicos que interagem nos hospitais - interno e externo - tem grande relevância.

Para a pesquisa aqui apresentada estabeleceu-se um estudo da comunicação externa dos hospitais da Região de Saúde correspondente a $13^{\mathrm{a}}$ Coordenadoria Regional de Saúde $(\mathrm{CRS})^{1}$, órgão ligado à Secretaria Estadual de Saúde do Rio Grande do Sul, Brasil, com sede regional em Santa Cruz do Sul e que engloba nove hospitais. Foram tomados quatro hospitais como recorte de pesquisa, com características distintas entre si. A pesquisa está ancorada nas teorias dos estudos culturais e das mediações, nos estudos de comunicação pública e de território. Tem caráter qualitativo, baseada em aplicações de questionário, entrevistas, análise documental, além de pesquisa bibliográfica. $\mathrm{Na}$ sequência, apresentam-se as bases conceituais para o estudo, seguidas da análise da comunicação externa dos hospitais e as conclusões obtidas.

${ }^{1} 13^{\mathrm{a}} \mathrm{CRS}$ é uma divisão administrativa estabelecida pelo estado do RS especificamente para a área da saúde. Os municípios que integram a $13^{a}$ CRS são: Candelária, Gramado Xavier, Herveiras, Mato Leitão, Pântano Grande, Passo do Sobrado, Rio Pardo, Santa Cruz do Sul, Sinimbu, Vale do Sol, Vale Verde, Venâncio Aires e Vera Cruz. Disponível em: http://www.saude.rs.gov.br/lista/170/13\%C2\%AA_CRS_\%28Santa_Cruz_do_Sul\%29. Acesso em: 08 jan.2017. 


\section{Cultura e Desenvolvimento}

A cultura é o que permeia toda nossa relação com o mundo. Raymond Williams (1958) criou a expressão "a cultura é ordinária", explicitando que é algo do cotidiano das pessoas. Stuart Hall "relaciona cultura à soma das descrições disponíveis pelas quais as sociedades dão sentido e refletem as suas experiências comuns" (HALL, 2003, p.134), tanto a produção artística e cultural como os modos de vida carregados de simbolização.

Hall (1997) faz uma diferenciação entre os aspectos substantivos e epistemológicos da cultura. Por substantivo entende-se o lugar da cultura na estrutura empírica real e na organização das atividades, instituições e relações culturais na sociedade, em qualquer momento particular, destacando seu vigor na contemporaneidade. Por epistemológico refere-se à posição da cultura para transformar nossa compreensão, explicação e modelos teóricos do mundo.

Os meios de produção e circulação cultural têm se ampliado, diversificado e expandido seu alcance por meio das tecnologias de comunicação e informação, especialmente após a revolução digital do final do século XX. Segundo Hall (1997), as indústrias culturais apoiadas na mídia sustentam circuitos globais de trocas econômicas, produção de bens, marketing e ideias. A expressão cunhada por Hall "centralidade da cultura" indica a forma como a cultura penetra em cada canto da vida social contemporânea. A mesma opinião é compartilhada por Martín-Barbero se referindo aos países da América Latina quando afirma que é "a centralidade incontestável que hoje ocupam os meios de comunicação em nossos países" (MARTÍN-BARBERO, 2003, p.12).

Para Martín-Barbero, os processos sociais estão demandando ajustes no objeto de estudo da comunicação e diálogo sobre a cultura transnacional, culturas populares, identidades, democracia, formação de novos sujeitos políticos e sociais, movimentos sociais que sinalizam para uma reconceitualização da cultura,

[...] que nos confronta com essa outra experiência cultural que é a popular, em sua existência múltipla e ativa não apenas na memória do passado, mas também na conflitividade e na criatividade atuais. Pensar os processos de comunicação neste sentido, a partir da cultura, significa deixar de pensá-los a partir das disciplinas e dos meios. Significa romper com a segurança proporcionada pela redução da problemática da comunicação à das tecnologias. (MARTÍN-BARBERO, 2003, p.287).

A cultura e os valores de cada sociedade influenciam os processos de desenvolvimento de cada região. Reconhece-se que a cultura e o desenvolvimento 
regional são termos relacionados. As questões que dizem respeito à dimensão cultural do desenvolvimento regional, conforme Felippi e Brandt (2016), são complexas e manifestam-se de diferentes formas nos territórios, que é onde ocorre a materialização das especificidades culturais de cada grupo.

Lago e Rotta (2017, s/n.), ao abordarem esta relação, relembram que "o desenvolvimento é um fenômeno localizado, multidimensional e complexo que implica um processo de transformação da estrutura produtiva, das relações sociais, das instituições, da organização política, das bases culturais e da própria relação dos seres humanos com a natureza". Cultura, deste modo, não pode ser vista como instrumental ao desenvolvimento, mas é fundamental que se compreenda como as sociedades significam o mundo e como refletem esses significados em seus comportamentos, de modo a pensar o desenvolvimento levando em conta potencialidades que se mostrem nos distintos grupos humanos.

\section{Comunicação e Saúde na relação com o território}

A comunicação na área da saúde traz consigo aportes culturais que se refletem na comunicação desenvolvida no âmbito da saúde pública e privada. Para Araújo e Cardoso (2007), o campo da comunicação e saúde é constituído pelos elementos de cada um separadamente, porém na sua interface. Assim, todo o aparato teóricoconceitual e metodológico da comunicação adquire pertinência, articulando e operando interesses do campo da saúde.

$\mathrm{Na}$ saúde pública, a comunicação não se dissocia da noção de direito, é dirigida a cidadãos, objetiva o aperfeiçoamento de um sistema público de saúde em todas as suas dimensões e a participação efetiva das pessoas nessa construção. Os princípios doutrinários do Sistema Único de Saúde (SUS) são a universalidade, equidade e a integralidade. Os princípios organizativos são a descentralização, hierarquização e participação.

No Brasil, segundo Almeida (2005), o direito universal à saúde não se efetiva igualmente em todos os lugares, pois o SUS se concretiza de maneira incompleta e seletiva no território, de modo geral, seguindo as tendências regionais de concentração e escassez populacional, econômica e das modernizações técnicas, científicas e informacionais, que caracterizam o meio geográfico.

Além das restrições políticas e financeiras que marcaram a implantação do SUS, acrescenta-se também aquela imposta pela dimensão territorial com 8,5 milhões de quilômetros quadrados. Por território entende-se:

[...] a extensão apropriada e usada. Mas o sentido da palavra territorialidade como sinônimo de pertencer a aquilo que nos pertence [...] esse sentimento de 
exclusividade e limite ultrapassa a raça humana e prescinde a existência do Estado. Assim, essa ideia de territorialidade se estende aos próprios animais, como sinônimo de vivência e reprodução. Mas a territorialidade humana pressupõe também a preocupação com o destino, a construção do futuro, o que, entre os seres vivos é privilégio do homem. [...] O que interessa é então o território usado, sinônimo de espaço geográfico. (SANTOS e SILVEIRA, [destaque do autor] (2003, p.19-20).

Os lugares e regiões mais empobrecidos e menos atrativos para o grande capital, conforme Almeida (2005), são também aqueles que apresentam menor atratividade e capacidade de investimentos em saúde, maiores dificuldades de atração e fixação de profissionais de saúde, menor capacidade de oferta assistencial pública e privada e maiores dificuldades relacionadas a gestão, ao financiamento e o planejamento do SUS.

Apesar de constar como princípio organizativo do SUS, desde o princípio de sua construção, a estratégia da regionalização da saúde só começou a ser delineada na diretriz nacional a partir dos anos 2000, conforme Albuquerque (2013). As dificuldades referentes à plena implantação da regionalização "envolvem também a aquisição de direitos cidadãos que tem a ver com a luta pelo desenvolvimento do país e consolidação de um espaço de proteção social”, (AGUIAR, 2011, p.150).

A região da $13^{a}$ CRS conta com nove hospitais, distribuídos em 13 municípios, que totalizam 826 leitos para uma população de 345.317 habitantes, conforme consta no site da Secretaria Estadual de Saúde (2017, < http://www.saude.rs.gov.br/crs>). Destes municípios, seis não possuem hospital, sendo necessário que a população se desloque para buscar atendimento. No maior município da região, Santa Cruz do Sul, estão em operação três hospitais e são ofertadas diversas especialidades médicas, caracterizando um polo de saúde regional.

Os hospitais da região vão de grande a pequeno porte e realizam atendimentos em âmbito local e regional. Como objeto deste estudo, foram definidas quatro instituições, apresentadas a seguir, com distintas características de porte, gestão e composição administrativa para abranger um contexto plural e representativo.

O Hospital Santa Cruz (HSC), com sede em Santa Cruz do Sul, é de grande porte, com 232 leitos. É também o único hospital de Ensino da região, sendo ligado ao curso superior de medicina da Universidade de Santa Cruz do Sul (UNISC), também sediada no município. Quanto à natureza administrativa, é entidade filantrópica, sem fins lucrativos, reconhecida como de Utilidade Pública. É referência regional nas áreas cardiovascular, traumatologia/ortopedia e gestantes de alto risco. Mantêm a única Unidade de Terapia Intensiva (UTI) pediátrica disponível na região. Atende SUS, convênios e particular.

O Hospital Ana Nery (HAN), também localizado em Santa Cruz do Sul, possui 90 leitos, sendo considerado de médio porte. É referência regional em oncologia e 
disponibiliza na região todas as etapas do tratamento do câncer, desde o diagnóstico, cirurgias, quimioterapia e radioterapia. É uma entidade filantrópica, sem fins lucrativos, reconhecida como de Utilidade Pública. Atende SUS, convênios e particular.

Outra instituição elencada na pesquisa foi o Hospital Regional do Vale do Rio Pardo (HRVRP), situado no município de Rio Pardo. A casa de saúde possui 93 leitos e é o único da região a atender exclusivamente pelo SUS. É referência regional em traumatologia/ortopedia, saúde mental e urgência e emergência. Desde 2014, a Fundação Hospitalar Getúlio Vargas (FHGV), fundação de direito privado sem fins lucrativos, assumiu a gestão do hospital, compartilhada com a Prefeitura. Em dezembro de 2017 a instituição passou a ser administrada pela Associação Brasileira de Assistência Social, Saúde e Inclusão.

Já o Hospital Vera Cruz (HVC), com sede no município de Vera Cruz, é um hospital de pequeno porte, disponibilizando 36 leitos. A instituição é gerida pela Fundação de Saúde Dr. Jacob Blész, entidade privada sem fins lucrativos, que possui certificado de filantropia. Atende SUS, convênios e particular.

\section{Aspectos metodológicos da pesquisa}

A metodologia de trabalho é baseada na teoria das mediações, aqui tomada a partir dos estudos culturais, desenvolvido por Jesús Martín-Barbero (2003), valendo-se, para a análise, dos estudos de produção jornalística e dos critérios de comunicação pública. A metodologia proposta por Martín-Barbero aborda o processo de comunicação a partir da sua integralidade, sem etapas estanques, mas sim momentos relacionados e interligados, atravessados por mediações.

A teoria das mediações é proposta na década de 1980 e vem sendo constantemente revisada nas décadas seguintes por seu autor, Jesús Martín-Barbero, sendo que para esta pesquisa optou-se pelo mapa das mediações proposto na década de 1990. Nesse, o autor expande sua compreensão de mediações. De um modo geral, a teoria das mediações propõe deslocar o olhar dos meios para o entorno que envolve o processo de comunicação. Afinada com os estudos culturais, expressa que os meios de comunicação não instituem e delimitam uma relação unilateral entre um emissor dominante e um receptor dominado. Entre esses dois "polos" há uma forte troca de intenções na cadeia da comunicação. Isto é, os conteúdos culturais são responsáveis, juntamente com a vivência individual, pelos repertórios que cada sujeito possui para interpretar a realidade, inserido numa certa cultura.

Na revisão da teoria das mediações, Martín-Barbero (2003), aprimora seu estudo e propõe um novo mapa das mediações do processo comunicativo contemplando as "lógicas de produção", os "formatos industriais", as "competências de recepção" (consumo) e as "matrizes culturais". Esses momentos do processo de comunicação 
estão mediados pela tecnicidade (situada entre as "lógicas de produção" e os "formatos industriais"), a "ritualidade" (entre os "formatos industriais" e as "competências de recepção"), a "sociabilidade" (entre as "competências de recepção" e as "matrizes culturais") e a "institucionalidade" (entre as "matrizes culturais" e as "lógicas de produção").

Por meio do Mapa das Mediações (Figura 01), o autor busca reconhecer que os meios de comunicação constituem hoje espaços-chave de condensação e intersecção de múltiplas redes de poder e de produção cultural, mas, ao mesmo tempo, alertar contra o pensamento único que legitima a ideia de que a tecnologia é hoje o grande mediador entre as pessoas e o mundo, quando o que a tecnologia medeia hoje, de modo mais intenso e acelerado, é a transformação da sociedade em mercado.

\section{Figura 01 - Mapa das Mediações}

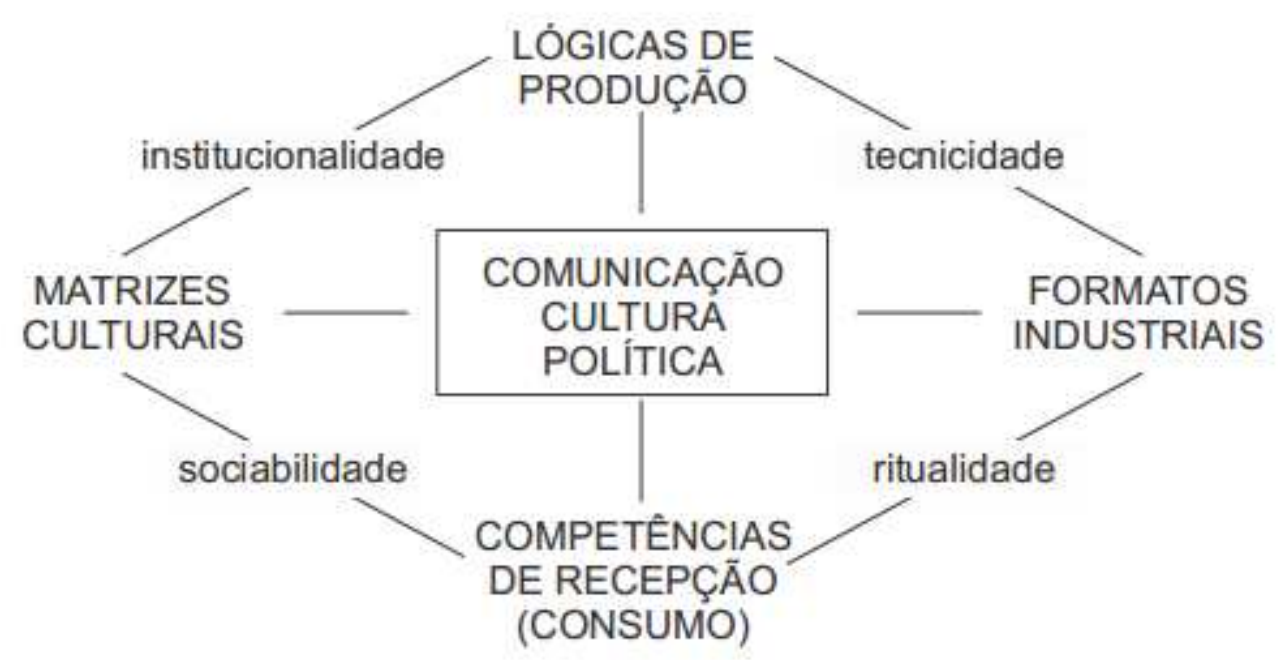

Fonte: MARTÍN-BARBERO, Jesús. Dos meios às mediações: comunicação, cultura e hegemonia. Rio de Janeiro: UFRJ, 2003, p.16.

As "lógicas de produção" são o que estrutura a produção, deixam vestígios no formato e nos modos como são significadas e recicladas as demandas oriundas dos públicos e seus diferentes usos. Contemplam o processo produtivo da comunicação hospitalar - serviços de comunicação das instituições -, as relações entre os profissionais envolvidos, a infraestrutura disponível, as políticas de comunicação na relação com as normativas de saúde e a estrutura empresarial das operadoras de saúde (no caso, os hospitais) e o histórico da condução da comunicação. Este momento é mediado pela "institucionalidade", entendida como a mediação que diz 
respeito a regulação dos discursos, que dá conta das relações de poder dos grupos sociais, políticos e econômicos na instância da produção dos meios de comunicação. A "institucionalidade" do Estado, por exemplo, está fortemente presente na saúde e nos hospitais através da legislação, normas, condutas e políticas que orientam o setor.

Os "formatos industriais", por sua vez, são compreendidos como as mídias e seus formatos, incluem os gêneros, como o jornalístico, a publicidade e o marketing, que estão sendo acionados pelos hospitais para efetivação da sua comunicação. Neste momento do processo de comunicação, o mapa propõe pensar a "tecnicidade", que contempla aspectos técnicos da produção da comunicação, como a inserção de (novas) tecnologias e as ferramentas empregadas na interação com o público. A comunicação é responsável por tornar visíveis todas as formas de inovações que permeiam o âmbito da produção, as quais irão afetar os seus discursos e formas, além dos modos de perceber e sentir os receptores, segundo Jacks (2008).

Com base nos dados coletados em campo a partir da proposta teórico-metodológica do mapa das mediações, a análise da presença da concepção de comunicação pública se dá a partir de quatro categorias selecionadas dentre as propostas por Zémor (1995): a) interesse público, b) divulgação dos serviços oferecidos pelas instituições, c) transparência e d) diálogo com o cidadão. Por interesse público busca-se compreender se a instituições privilegiam assuntos de interesse da sociedade nas suas comunicações. A divulgação dos serviços oferecidos pelas instituições espera que assim o cidadão tenha conhecimento dos serviços disponíveis naquele hospital. A transparência posta como premissa para a divulgação de informações relacionadas à gestão dos recursos públicos e, por último, o diálogo com o cidadão como forma de se estabelecer uma comunicação pública cidadã.

A pesquisa de campo envolveu a aplicação de um questionário a todos os gestores de comunicação dos nove hospitais da região e, posteriormente à seleção de quatro instituições para estudo, foi realizada uma entrevista com os gestores administrativos e de comunicação, totalizando oito entrevistas semiestruturadas. Os informantes responderam sobre o funcionamento do hospital e da comunicação interna e externa, de caráter informativo ou publicitário. Ainda, foram levantados e observados os materiais de comunicação externa, de caráter massivo ou segmentado, excetuando a comunicação direta e interpessoal feita em pontos de atendimento das instituições hospitalares, bem como em ações externas, como estandes de eventos. Os materiais de comunicação produzidos pelos quatro hospitais selecionados para compreender os "formatos industriais" na relação com sua produção, projetando seu consumo no território, também foram observados. Os entrevistados são identificados conforme o quadro 01.

\section{Quadro 01 - Identificação dos entrevistados}




\begin{tabular}{|l|l|l|}
\hline $\begin{array}{l}\text { Gestor HSC = Diretor Administrativo Hospital } \\
\text { Santa Cruz }\end{array}$ & $\begin{array}{l}\text { Gestor de Comunicação HSC = Coordenador de } \\
\text { Comunicação HSC }\end{array}$ \\
\hline $\begin{array}{l}\text { Gestor HAN = Diretor Executivo Hospital Ana } \\
\text { Nery }\end{array}$ & $\begin{array}{l}\text { Gestor de Comunicação HAN = cargo de Analista HAN } \\
\text { Gestor HRVRP = Diretor Administrativo } \\
\text { Hospital Regional do Vale do Rio Pardo }\end{array}$ & $\begin{array}{l}\text { Gestor de Comunicação HRVRP = Coordenador de } \\
\text { Comunicação HRVRP }\end{array}$ \\
\hline $\begin{array}{l}\text { Gestor HVC = Diretor Administrativo Hospital } \\
\text { Vera Cruz }\end{array}$ & $\begin{array}{l}\text { Gestor de Comunicação HVC }=\text { Coordenador de } \\
\text { Desenvolvimento Humano }\end{array}$ \\
\hline
\end{tabular}

Fonte: Elaborado pelas autoras da pesquisa em 2016.

Identifica-se o nome das instituições e os cargos dos profissionais que concederam as entrevistas, pois entende-se que o conteúdo das falas representa o posicionamento das instituições.

\section{As "lógicas de produção"}

A compreensão do funcionamento das "lógicas de produção" mobiliza um tríplice questionamento, conforme Martín-Barbero (2003), sobre (a) a estrutura empresarial em suas dimensões econômicas, ideologias profissionais e rotinas produtivas; sobre (b) sua competência comunicativa - capacidade de interagir com públicos, audiência, consumidores; e, muito especialmente, (c) competitividade tecnológica: usos da tecnologia dos quais depende hoje em grande medida a capacidade de inovar nos "formatos industriais".

Compreendem-se as dimensões da estrutura empresarial ou institucional dos hospitais como a sua constituição enquanto empresa e o reflexo disso nas suas estruturas de comunicação. As quatro instituições pesquisadas afirmam que buscam qualificar a gestão para melhorar os resultados operacionais. HSC, HAN e HVC atuam com base nos seus planejamentos estratégicos, enquanto o HRVRP segue o plano da FHGV e não possui um planejamento específico para o hospital. Todos os hospitais pesquisados possuem comissões internas para tratar temas como melhorias dos processos e segurança.

A estrutura empresarial dos hospitais tem reflexos diretos na maneira como conduzem a comunicação institucional, as ferramentas que utilizam e os recursos disponíveis. Nas entrevistas ficou evidenciado que a crise política e econômica, especialmente no Rio Grande do Sul, iniciada em 2015, impactou nos serviços de comunicação dos hospitais com a redução de profissionais, de canais de comunicação próprios e de ações de comunicação que demandam recursos 
financeiros e humanos. Apesar das dificuldades do momento, não consideram extinguir o serviço de comunicação.

A competência comunicativa, segundo aspecto do tripé anteriormente apresentado, reflete a estrutura empresarial dos hospitais no que diz respeito ao seu porte e atendimentos públicos e privados. O serviço ou setor de comunicação possui nomenclaturas diferentes conforme a instituição e o ponto em comum é que são setores posicionados no organograma das instituições com ligação ou subordinação à direção. Possuem amplo acesso aos gestores e referem que isso é importante para a fluidez e bom resultado do trabalho.

As diferentes políticas de comunicação das instituições podem ser observadas inclusive na forma de se referir ao público. Em um hospital, os pacientes são chamados de usuários e, em outro, de clientes. Em um local, os funcionários são relacionados como colaboradores e, em outro, de trabalhadores.

É unânime entre os gestores administrativos o reconhecimento da importância da comunicação para os hospitais.

É muito importante, pois ele consegue colocar dentro de uma linguagem que seja simples, adequada para nos relacionarmos com o público externo, principalmente os usuários, principalmente em momentos críticos (Gestor HSC).

O Gestor do HVC tem opinião semelhante:

A comunicação é muito importante, pois aproxima ou não as pessoas e trabalha a imagem da empresa na comunidade (Gestor HVC).

A competência comunicativa e o esforço da comunicação hospitalar também estão em conquistar o apoio e reconhecimento da sociedade sobre a importância do trabalho dos hospitais e as dificuldades que enfrentam, uma vez que trabalham com recursos públicos e recebem doações da comunidade. As entrevistas e a pesquisa documental revelaram que os três hospitais filantrópicos destacam em seus veículos de comunicação a busca por doações da comunidade, seja em dinheiro, seja em alimentos, materiais ou serviço voluntário. A sociedade tem em sua prática cultural o auxílio às entidades filantrópicas e assistenciais desde a fundação desses hospitais que surgiram a partir de entidades religiosas ou de mobilizações das comunidades.

No que diz respeito à rotina do serviço de comunicação, é centrada na atuação do profissional de comunicação, pois recebe as demandas e também é o principal articulador de pautas e ações. O HSC possui uma equipe de comunicação que conta com um jornalista, uma publicitária e uma estagiária de relações públicas que 
trabalham com comunicação interna e externa. O HAN conta com uma relações públicas e uma administradora que atuam com comunicação interna e externa, sendo que terceirizam o serviço de uma agência de publicidade. A equipe do HRVP conta com um publicitário, dois jornalistas e uma estagiária de publicidade sediados no município de Sapucaia do Sul, sede da FHGV, distante 168 quilômetros de Rio Pardo. Já o setor de comunicação do HVC é conduzido por uma relações públicas que desempenha também a função de coordenadora de recursos humanos e ouvidora.

Os gestores de Comunicação revelaram possuir autonomia para conduzir a maior parte das atividades da área, sendo os gestores das instituições informados e, em alguns casos, consultados sobre os procedimentos. Essa independência é apontada como resultado do longo tempo de atuação no segmento e ao relacionamento de confiança estabelecido. Afirmam que as demandas da imprensa são tratadas como prioridade em função da rotina específica desses veículos. Além das pautas proativas dos hospitais, a imprensa também faz busca de informações. Os serviços de comunicação dedicam pouco tempo para avaliação e mensuração dos resultados alcançados.

O foco das ações de comunicação nos três hospitais filantrópicos, no momento das entrevistas realizadas, estava voltado para a divulgação dos serviços de saúde que os hospitais disponibilizam, como laboratório de análises clínicas, exames de imagem como raio x, ecografia, tomografia, endoscopia, entre outros. O objetivo é atrair pacientes de planos de saúde, pois é uma maneira de aumentar os ganhos dos hospitais.

A realidade da maioria dos hospitais consiste no atendimento de pacientes pelos SUS, planos de saúde e pacientes que pagam por serviços de forma particular. Essa dualidade entre público e privado está presente no dia a dia dos hospitais que buscam o paciente de plano de saúde e privado/particular, por meio dos quais os procedimentos são melhor remunerados, para diminuir o déficit causado pelos valores pagos pelos procedimentos via SUS que não são reajustados há 20 anos e tiveram cortes de incentivos públicos. "Essas questões levam à problematização das dimensões políticas e econômicas que envolvem o par público-privado e, junto com este, os demais binômios existentes" (CALIXTRE e FILHO, 2014, p.614). O Estado não consegue prover a estrutura de saúde necessária integralmente, então busca as instituições filantrópicas ou privadas para suprir a demanda da população. Para Martín-Barbero (2003), a "institucionalidade” afeta a regulação dos discursos tanto do Estado quanto dos cidadãos. O Estado busca a estabilidade para a ordem constituída enquanto os cidadãos buscam defender seus interesses e fazerem-se reconhecer, reconstruindo o social permanentemente. Os diferentes regimes da "institucionalidade" estão presentes nas discussões que envolvem o SUS e tem a comunicação como aliada para discutir com o Sistema com a sociedade. "A comunicação é uma questão de meios, de produção de discursos públicos, cuja 
hegemonia encontra-se paradoxalmente do lado dos interesses privados" (MARTÍN-BARBERO, 2003, p.18).

O posicionamento dos hospitais nas relações com os demais agentes da saúde no âmbito da comunicação evidencia a postura dessa instituição e também os problemas presentes na organização do SUS ("institucionalidade"). Não existe, no âmbito da comunicação, uma cooperação entre os órgãos de saúde da região para tratar de temas de interesse da sociedade, segundo os entrevistados.

Assim como o Estado, a sociedade também tem uma estreita relação com a saúde e os hospitais. Essa relação traz traços culturais que se evidenciam, por exemplo, na prática de acompanhamento dos familiares e amigos hospitalizados. A força dessa prática cultural se expressa através desse hábito enraizado na vida dessa sociedade, que, numa dada situação identificada na pesquisa, se manifestou contrária a mudanças neste sentido. Martín-Barbero (2003), entende que o receptor não é passivo diante das mensagens, é também um produtor a partir do seu repertório individual.

No cotidiano não se pode separar a experiência institucional e social. As mediações não acontecem de forma independente, pois se dissolvem em um mesmo patamar simbólico. Em algumas situações, salienta Cardoso (2016), pode ser observada a predominância de uma mediação sobre a outra num processo que aciona posicionamentos e discursos diversos dos sujeitos segundo as circunstâncias.

No seu dia a dia os hospitais se relacionam com diversos órgãos governamentais em várias esferas públicas e empresas privadas de saúde e buscam equilibrar as partes para continuar atuando e atender os pacientes da sua cidade ou região. Esse delicado equilíbrio é constantemente tensionado por questões de ordem econômica, política, midiática, religiosa ou cultural. A comunicação com esses públicos é fundamental e os hospitais tem se apropriado de novas tecnologias para atender essas demandas.

A competitividade tecnológica, terceiro ponto do tripé apontado por MartínBarbero (2003), dentro das "lógicas de produção", é voltada à inovação, usos de tecnologias e a competência comunicativa. O uso das redes sociais e canais de comunicação gerados a partir da internet ampliaram a comunicação das instituições e possibilitaram novas abordagens em diversas escalas.

Se você não está se comunicando com as mídias sociais, está deixando uma parcela cada vez maior da população fora da conversa. Não se trata de mídia social contra imprensa convencional. Esses não são canais concorrentes. Trata-se de um processo cumulativo. (SULLIVAN, 2012, p.51). 
As redes sociais têm sido usadas pelas instituições na sua comunicação com a sociedade em alguns casos em maior intensidade e outros em ações mais pontuais. São ferramentas dinâmicas e de baixo custo de implantação e manutenção, o que é favorável ao segmento da saúde. Elas representam uma comunicação direta com o público sem a mediação de um veículo de comunicação.

A competitividade tecnológica não trata apenas das mídias digitais, mas também dos meios mais adequados para cada contexto e necessidade. Ao mesmo tempo em que as instituições são adeptas dessas novas mídias, as tradicionais, como rádios e jornais, mantêm sua posição de destaque regional. O rádio, pela facilidade de acesso, tem forte penetração na área rural dos municípios, sendo a tecnologia mais favorável para essa população. Quando a pauta exige uma ampla repercussão, os veículos preferenciais dos hospitais são os tradicionais de alcance regional e que replicam o conteúdo nas suas plataformas digitais.

\section{Os "formatos industriais"}

Percorrendo o Mapa das Mediações chega-se aos "formatos industriais": discursos, gêneros, programas e grades, que “[...] regulam a interação entre os espaços e tempos da vida cotidiana [...] que implica, da parte dos meios, uma certa capacidade de impor regras aos jogos entre significação e situação" na compreensão de (MARTÍN-BARBERO, 2003, p. 19). Quanto aos "formatos industriais", os compreendemos como o conteúdo que é formatado para as mídias e transformado em textos jornalísticos, relatórios, posts na internet, entre outros formatos e que estão sendo usadas pelos hospitais para efetivar a sua comunicação.

A partir da implantação de serviços de comunicação nos hospitais, em meados dos anos 2000, foram sendo incorporadas ferramentas conforme a necessidade e as possibilidades de cada instituição. Todos os hospitais possuem site, no qual divulgam notícias, ações institucionais, orientações para pacientes, convênios, procedimentos, informações de contato e publicações institucionais. O HRVRP possui um espaço dentro do site FHGV com apenas uma foto da fachada do prédio e informações básicas como endereço e telefone.

Seguindo as inovações e tendências das mídias sociais na última década, o Facebook alcançou um amplo espaço nas instituições, especialmente no Brasil, país que desponta no uso desta rede social. O HSC, HAN e HRVRP possuem páginas no Facebook. O HVC não tem página no Facebook e alega que a ferramenta não tem penetração com o seu público e não teria condições de manter e interagir adequadamente com essa mídia. Dos três hospitais que possuem páginas nesta rede social, os gestores de Comunicação consideram-na aquela que consegue ter maior alcance junto aos seus públicos. Esse reconhecimento se deve por vários motivos, entre eles o baixo custo de manutenção e o fácil gerenciamento. É utilizado como 
ferramenta de comunicação tanto institucional, quanto para os conteúdos internos, como divulgação de informações sobre folha de pagamentos, dissídios e ações internas. Acredita-se que, em meio à crise dos hospitais, as redes sociais ganham força também por serem mídias de custo baixo para os hospitais manterem em detrimento de outras mídias e ações (como a publicidade).

Outro aspecto positivo do Facebook mencionado por três entrevistados é a possibilidade de se comunicar com a sociedade sem a mediação dos meios de comunicação.

Quando você envia um release para o jornal você fica na dependência do espaço e da vontade do editor (Gestor de Comunicação HSC).

A “tecnicidade" é responsável por tornar visível todas as formas de inovação que permeiam o âmbito da produção, as quais indubitavelmente irão afetar seus discursos e formas - sua gramática - além dos modos de sentir e perceber seus receptores conforme Martín-Barbero (2002).

A sociedade civil brasileira se organiza cada vez mais para falar diretamente à opinião pública sem intermediários, fazendo uso das redes sociais e mídias próprias coordenadas por profissionais de comunicação. Conforme Sant'Anna (2007), os produtos das assessorias de comunicação encontram excelente aceitação por parte da mídia tradicional, pois além de apresentarem conteúdo satisfatório, por serem gratuitos, se mostram economicamente interessantes às estruturas reduzidas das redações jornalísticas tradicionais. Também sinaliza uma luta pelo espaço público e por se fazer ouvir através da mídia comercial.

Ao interagir com a dinâmica produtiva da mídia, Faria (2002) afirma que as organizações ressentem-se do viés conflitivo e negativo da notícia. Os acontecimentos que viram notícias negativas têm uma ampla cobertura e as conquistas e iniciativas positivas não têm o mesmo espaço, é o comentário comum dos gestores de comunicação.

A imprensa regional nos procura quando a desgraça virou manchete. Daí a busca por notícias ruins é incansável. Mas para divulgar coisas boas não (Gestor de Comunicação HVC).

Mesmo os profissionais com vários anos de experiência e cientes dos critérios dos fatos para serem notícia se frustram com essa posição:

Eu entendo, é a lógica do mercado (Gestor de Comunicação HVC). 
Os hospitais mantêm vários outros canais de comunicação e se utilizam de diversos "formatos industriais" para atenderem às demandas de comunicação de um público heterogêneo que se relaciona com as instituições e, na medida do possível, prevendo a compreensão das práticas culturais e sociais de cada local.

No HSC, o serviço de comunicação coordena o serviço de assessoria de imprensa, que é o relacionamento estreito com os veículos de comunicação, com envio de pautas, entrevistados e relises ${ }^{2}$. Ainda produz um jornal institucional trimestral impresso e em versão digital, responde pelo e-mail institucional, site, página no Facebook, Instagran, Flicker, Youtube, cobertura de eventos do hospital e, eventualmente, elabora anúncios publicitários. O hospital possui um serviço de Ouvidoria, no entanto, o mesmo não tem vínculo com o setor de Comunicação.

O serviço de comunicação do HAN responde também pelo Setor de Qualidade do hospital. Dispõe de assessoria de imprensa, site, e-mail institucional, página no Facebook, participação em eventos, publicidade e o Serviço de Relacionamento com o Cliente (ouvidoria).

A equipe da FHGV atende às demandas de comunicação interna e externa do HRVRP e das nove unidades hospitalares e Unidades de Pronto Atendimento geridas pela FHGV. Administram a assessoria de imprensa, um boletim eletrônico semanal, site, página do Facebook e eventos. A Ouvidoria da instituição se reporta diretamente ao Ministério da Saúde.

O HVC conta com assessoria de imprensa, e-mail institucional, site, revista impressa e eletrônica bianual, participação em eventos, publicidade, coluna semanal no Jornal Arauto, de Vera Cruz. É responsável também pela Ouvidoria.

De um modo geral, é notícia produzida e veiculada em mídias próprias dos hospitais ou na mídia comercial que recebe os materiais dos hospitais sobre acontecimentos relacionados aos serviços de saúde dos hospitais - públicos ou privados -, como aquisição de equipamentos, funcionamento dos serviços, campanhas de saúde ou de arrecadação financeira, ou novidades em relação ao repasse de recursos. A pauta da crise financeira dos hospitais é histórica e, portanto, recorrente, estando presente no momento da realização desta pesquisa e verbalizada pelos entrevistados. As falas demonstraram não só a elaboração de materiais (relises e notícias) e ações (caminhadas, abraço ao hospital, faixas de protesto, etc.) visando a divulgação da situação e a busca de adesão da sociedade à causa dos hospitais, bem como a contração dos setores de comunicação dos hospitais nos últimos três anos, com restrições de operação, diminuindo pessoal e ações/produtos.

\footnotetext{
${ }^{2}$ Relise ou release é um texto com formato de notícia produzido e enviado pelas assessorias de comunicação à mídia como forma de divulgação de informações.
} 
Para além dos canais de comunicação próprios, os hospitais dialogam com a sociedade via mídia tradicional, com mais intensidade com os veículos de comunicação locais ou regionais, e menos com a mídia estadual e nacional. $\mathrm{Na}$ região em estudo, há jornais, rádios e sites comerciais de abrangência local, e jornais, emissoras de rádio e de televisão, além de sites de abrangência regional. Destaca-se um grupo de comunicação regional, o Grupo Gazeta, com quase uma dezena de mídias, que tem certa liderança tanto na abrangência de público, como no prestígio que goza, e é para este grupo que convergem a maior parte das produções dos setores de comunicação dos hospitais. Outro destaque é a sucursal do maior grupo de comunicação do Rio Grande do Sul, a Rede Brasil Sul de Comunicação, e seu braço televisivo, a RBS TV, que pela força que a televisão tem no Brasil, mobiliza os setores de comunicação dos hospitais por seus espaços. As rádios também gozam de atenção por parte dos hospitais decorrente também da força que o rádio tem historicamente no país e da sua facilidade de acesso, inclusive no espaço rural.

\section{Comunicação Pública}

Para identificar a presença da concepção de comunicação pública na comunicação hospitalar estudada elencou-se quatro categorias a partir da obra de Zémor (1995): a) interesse público, b) divulgação dos serviços, c) transparência e d) diálogo com o público. O interesse público é o tema de interesse imediato e de uma grande parte dos cidadãos. A saúde pública e os assuntos relacionados a ela são reconhecidamente de interesse público. A divulgação de serviços é uma obrigação dos órgãos públicos e instituições que atuam em conjunto para esclarecer os cidadãos dos seus direitos e deveres.

A transparência na gestão e na comunicação das ações decorrentes dela são um ponto importante da comunicação pública. O diálogo com o a sociedade a partir das possibilidades de interação com o cidadão e troca de informações explicitam a posição de receptividade para contribuições e críticas.

A comunicação pública acontece no espaço formado pelos fluxos de informação e de interação entre os agentes públicos e atores sociais em temas de interesse público e promove a viabilização do direito social coletivo e individual ao diálogo, à informação e à expressão.

O uso da comunicação pública está associado à busca de melhorar a vida das pessoas pela comunicação. "Praticar a comunicação pública implica assumir espírito público e privilegiar o interesse coletivo em detrimento de perspectivas pessoais e corporativas", (DUARTE, 2012, p.61).

\section{Figura 2 - Ambiente de comunicação de interesse público.}




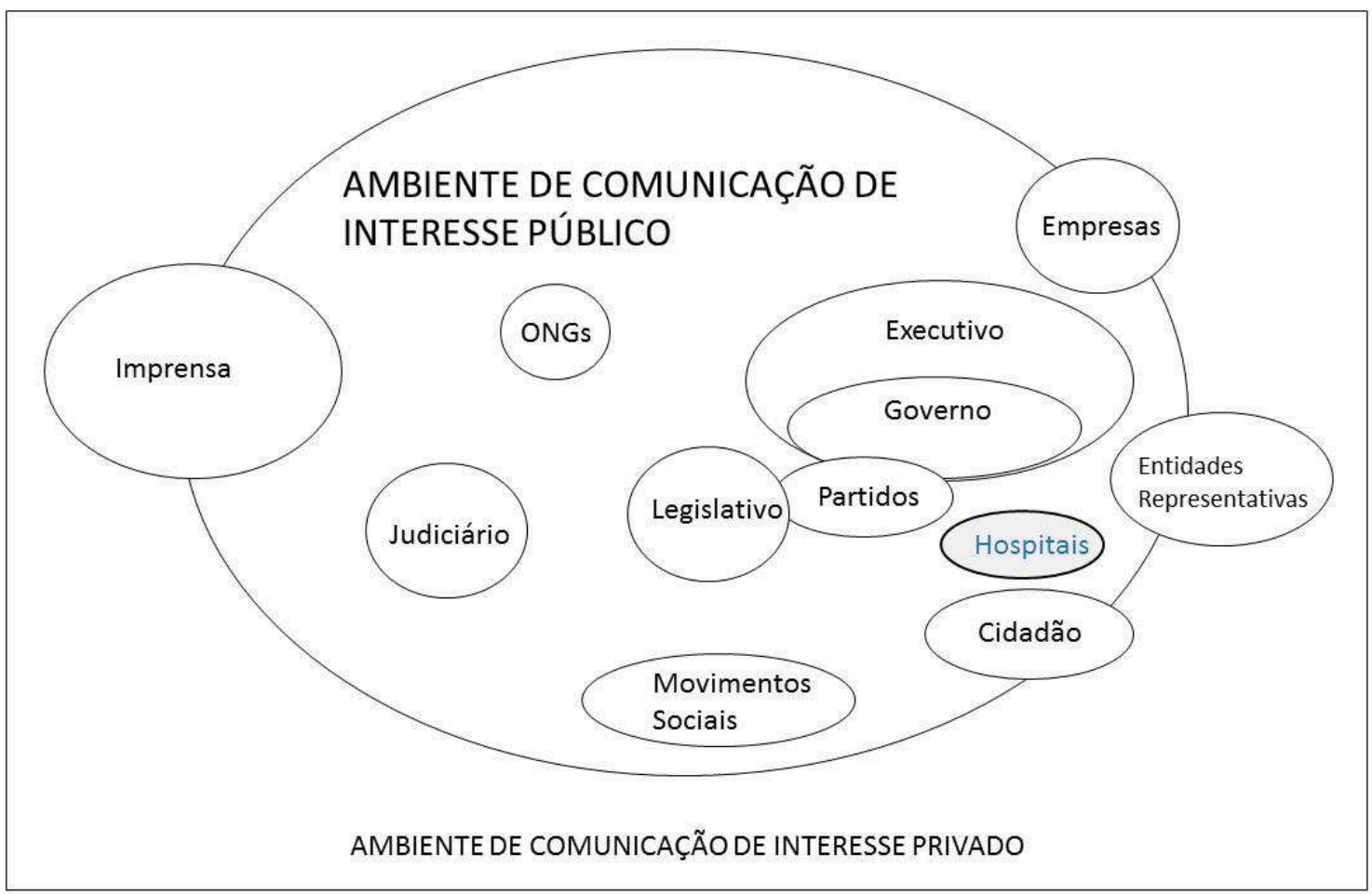

Fonte: Modelo de campo da comunicação pública adaptado pelas autoras em 2016 a partir de Duarte (2007).

\section{a) Comunicação de interesse público}

Quando questionados sobre o interesse público na sua forma de comunicação, todos entrevistados entendem que está presente na comunicação hospitalar. O tema saúde por si só já desperta a atenção do público e da imprensa como um assunto de interesse comum.

É uma pauta natural e de interesse público (Gestor de Comunicação HSC).

A mídia comercial parece ser a via preferencial dos hospitais para divulgarem assuntos que estão em evidencia no momento, como crise na saúde pública e o atraso no recebimento de recursos governamentais. A escolha pela mídia parte do pressuposto de que a pauta interessa à sociedade e assim terá espaço na mídia.

Também é preciso considerar o esforço dos assessores de comunicação dos hospitais em trabalhar as pautas de forma que se tornem atrativas para os veículos de comunicação com valor-notícia relevantes, fotos e entrevistados acessíveis. "Quanto maior o atendimento aos critérios de noticiabilidade a notícia apresentar, mais próxima ela estará de atingir o conceito de interesse público" (ROSSIGNOLLI; ASSÊNCIO e CORDENONSI, 2013, p.5). As notícias 
direcionadas para as mídias são publicadas também nos canais de comunicação próprios.

O foco das pautas é a situação financeira e ao mesmo tempo a divulgação de novos equipamentos e serviços. Os dois temas soam contraditórias quando, um dia a notícia é a falta de recursos e no outro a aquisição de equipamentos e inauguração de serviços. A dinâmica do segmento da saúde exige que os assessores de comunicação consigam deixar bem claro as fontes de recursos e condições que viabilizaram essas aquisições.

Através da recorrente divulgação pela imprensa de notícias sobre as dificuldades financeiras dos hospitais, a sociedade fica sensibilizada pelo apelo das instituições por apoio financeiro por meio de eventos, rifas, pedidos de doação e pressão sobre os governantes. "As fontes institucionais agem intencionalmente para ocupar espaço na mídia, tornar-se visíveis e, assim, satisfazer as suas necessidades organizacionais" (MONTEIRO, 2002, p.159).

Para além do interesse público desses temas, também está intrínseca a busca por reforçar a imagem institucional diante da sociedade, a divulgação de serviços que buscam dar ciência para as pessoas dos recursos humanos e tecnológicos que a instituição dispõe. Além do interesse público, também está presente o interesse comercial de ter essa informação disseminada. A linha entre interesse público e privado é tênue e em alguns momentos parece se misturar.

Sob este arco de tensões, a saúde é vista tanto como um campo de práticas de saúde quanto como um setor de produção e consumo de bens e serviços. "Essa duplicidade constitui um espaço real de ação e disputa de projetos de diferentes estratos sociais por eles gerados e/ou a eles dirigidos", conforme (CALIXTRE e FILHO, 2015, p.613). Os autores apontam, ainda, que cada um deles vai produzindo no senso comum uma opinião pública, de base dicotômica, em favor do predomínio de um ou de outro modo de prestar assistência ou de cuidar da vida dos indivíduos e dos grupos.

\section{b) Divulgação de serviços}

A dualidade entre o público e privado, no caso dos hospitais em estudo, fica evidenciada na divulgação dos serviços disponíveis pelas instituições. Os hospitais, com intuito de se diferenciar um dos outros e atrair os pacientes para que venham realizar seus exames ou procedimentos, através de planos de saúde ou pagando diretamente, em determinado hospital, investem em formas de publicizar suas operações. 
Divulgam que possuem resolutividade e tecnologias de ponta à disposição da sociedade que, desta forma, não precisa se deslocar para grandes centros na busca por estes recursos. Essa lógica mercadológica existe, segundo o gestor administrativo do HSC, quando uma parcela da sociedade com alto poder aquisitivo acredita que os melhores recursos estão disponíveis apenas em grandes centros urbanos. Essa divulgação cumpre um duplo papel e pode se colocar como uma divulgação de interesse público e privado simultaneamente.

Nos sites dos hospitais estão fotos das melhores acomodações e facilidades que os hospitais oferecem. No entanto, a maioria dos pacientes é atendida pelo SUS em espaços aquém dos proporcionados de forma privada ou por meio dos planos de saúde. Essa postura na divulgação dos serviços disponíveis deixa a comunicação dúbia, pois aquela imagem é a realidade da minoria dos pacientes atendidos.

A divulgação por parte dos hospitais, em canais próprios e na mídia comercial, de serviços de interesse público, como doação de sangue, doação de órgãos, informações sobre prevenção ao câncer e outras doenças tem acontecido pontualmente em datas alusivas a esta ou aquela enfermidade. Essa lógica mercadológica estabelecida atende às duas partes - hospitais e imprensa - que conseguem nessas oportunidades espaços para essas notícias.

A publicização dos serviços oferecidos pelas entidades tem um papel importante na vida das pessoas, levando informações que podem impactar na sua condição de vida e de saúde. A responsabilidade na gestão e divulgação das informações, em especial na saúde pública, é fundamental para atender os interesses públicos. Há espaço para avanços em uma comunicação pública mais voltada à humanização do sistema de saúde, de boas práticas de gestão, condições de saúde e que não esteja, constantemente, com os holofotes sobre a situação econômica.

\section{c) Transparência}

Para além da transparência relativa ao uso dos recursos públicos e gestão, a postura da instituição quanto aos atores sociais também reflete essa premissa. Os hospitais em estudo se mostraram receptivos para participar dessa pesquisa, recebem visitas técnicas de estudantes e outros órgãos, relatam bom relacionamento com a mídia e instituições da sociedade.

No caso da divulgação de informações para a sociedade em geral, os meios digitais são os preferidos das instituições pela agilidade e custo de disponibilização e manutenção. No entanto, é perceptível a dificuldade em manter as informações atualizadas, sendo que, em alguns casos, a defasagem de informações financeira, por exemplo, completa dois anos. Ainda, essa forma de divulgação esbarra nas condições de acesso à internet da população. 
É importante observar que não é do dia a dia da maioria da população a interpretação de balanços financeiros, sendo fundamental a atenção à linguagem empregada. A acessibilidade das informações depende também da simplicidade das condições de uso dos dados, em especial a linguagem utilizada. A linguagem do agente público precisa estar atenta às preocupações e com a cultura do usuário diz Zérmor (2012).

\section{d) Diálogo com o público}

Além dos meios diretos de diálogo ou de coleta de opiniões mantidos pelos hospitais (pontos de atendimento, contato em eventos externos, etc.), em termos de mídias, o Facebook, segundo a maioria dos entrevistados, é a forma mais usada pela facilidade e agilidade do contato e retorno para dúvidas diversas sobre horários, endereços, procedimentos, entre outros aspectos. "A comunicação pública ou de interesse público não pode ser transgênica, mas plural, social e culturalmente diversa" (BUENO, 2012, p.150). A rede social tem se mostrado um canal interessante aos hospitais, seja pelo baixo custo, como pela resposta rápida do público, que visualiza, comenta e repassa para outros as informações, em que pese o fato de a internet não ser acessível a parte da população.

Apesar de não serem estudadas com destaque nesta pesquisa, os entrevistados mencionaram os eventos externos dos hospitais como bem presentes na aproximação com a sociedade e na obtenção de espaço na mídia, com a cobertura que ganham da mesma. Da mesma forma, as ouvidorias são um canal de comunicação bastante utilizado pelos pacientes e familiares quando estão dentro das instituições para fazer reclamações, críticas, sugestões e elogios. Os hospitais realizam pesquisas de satisfação com os usuários dos hospitais e utilizam esse indicador como parâmetro das suas atividades.

O público usuário se vale ainda de uma ferramenta interessante, o anúncio em jornal ou rádio e post em redes sociais para manifestar agradecimento pelo atendimento e serviços prestados pelos hospitais e profissionais de saúde. O relacionamento face a face dentro dos hospitais entre pacientes, familiares, profissionais de saúde e o Sistema de Saúde é onde o diálogo mais ocorre e, supõe-se, tem fortes componentes de comunicação pública.

\section{Considerações finais}

$\mathrm{Na}$ região da $13^{\circ} \mathrm{CRS}$, a comunicação hospitalar é uma realidade de aproximadamente vinte anos, que chegou a certas instituições muito recentemente, estando ainda em consolidação. Mesmo assim, a pesquisa identificou que os 
hospitais possuem um setor de comunicação instituído, com respaldo dos gestores, setor que administra diversos canais de comunicação e relaciona-se com a mídia e a sociedade na qual estão inseridos. Há um esforço institucional para que se faça a disputa pública pela visibilidade dos hospitais, seja tendo em vista a concorrência de uns com os outros e dos hospitais com os demais serviços de saúde ofertados na região, seja com outras instâncias de decisão política e econômica.

No entanto, as especificidades da saúde pública brasileira mediam os processos de comunicação realizados pelos hospitais, que acusam desde dificuldades financeiras, a relação sobreposta do privado no público, a centralidade dos hospitais no modelo de saúde nacional, até as dificuldades de implantação da política de saúde num país continental e num processo de gestão que vai da escala nacional à local.

Soma-se à mediação da "institucionalidade", a da "tecnicidade", instaurada sobre os processos de comunicação midiáticos, massivos ou segmentados. Antigas e novas mídias são acionadas para construir canais de comunicação com a sociedade. Neste sentido, vale a menção sobre a mídia regional que acolhe os materiais produzidos no âmbito dos hospitais, muito embora não fosse o foco desta pesquisa. As características da mídia em países como o Brasil, de natureza privada, cuja notícia é sua mercadoria e os critérios de publicação são baseados na busca da audiência, inibem a expansão do que se compreende por comunicação pública. Há brechas abertas pela mídia e buscadas pelos hospitais, que, por sua vez, expõem do mesmo modo suas contradições por meio da comunicação, quando ora comunicam, buscando atender os interesses públicos, ser transparentes e buscar o diálogo com a sociedade; ora utilizam os canais de comunicação como forma de propagandear seus serviços.

Destarte, a prática de comunicação externa dos hospitais reflete as contradições do sistema de saúde brasileiro - e do país, de um modo geral -, em que o Estado não consegue atender a demanda de saúde dos cidadãos por meio dos sistemas públicos e busca, através de contratos com a rede privada, a assistência para a população. As instituições, por sua vez, parecem buscar o equilíbrio entre sua natureza pública e privada, sendo que a comunicação hospitalar da região observada demonstra esse movimento, que tem contornos próprios no território estudado.

\section{Referências}

AGUIAR, Zenaide Neto. SUS: antecedentes, percurso, perspectivas e desafios. São Paulo: Martinari, 2011.

ALMEIDA, Eliza P. de. Uso do Território Brasileiro e os Serviços de Saúde no Período Técnico-Científico-Informacional. 2005.313f. Tese. (Faculdade de Filosofia Ciências e Letras) - Universidade de São Paulo, São Paulo, 2005. Disponível 
http:/ /www.geografia.fflch.usp.br/publicacoes/Geousp/Geousp18/teses\%20e\% 20Disserta $\%$ C3\%A7\%C3\%B5es.pdf>. Acesso em: 04 abr.2016.

ARAÚJO, I.; CARDOSO, J. M. Comunicação e Saúde. Rio de Janeiro: Editora Fiocruz, 2007.

BUENO, Wilson C. Comunicação, iniciativa privada e interesse público. In: DUARTE, Jorge (Org). Comunicação Pública: estado, mercado, sociedade e interesse público. São Paulo: Editora Atlas, 2012. p.134-153.

CALIXTRE, A.; FILHO, N. Cátedras para o desenvolvimento: patronos do Brasil. Rio de Janeiro: Ipea, 2014.

CARDOSO, Letícia C.M. As mediações no Bumba meu Boi no Maranhão: uma proposta metodológica de estudo das culturas populares. 2016.268f. Tese (Programa de Pós-Graduação em Comunicação Social) - Pontifícia Universidade Católica do Rio Grande do Sul, Porto Alegre, 2016. Disponível em:< http://tede2.pucrs.br/tede2/handle/tede/6694>. Acesso em 18 abr.2018.

CARVALHO, D. W.; FREIRE, M. T. M.; VILAR, G. Comunicação e saúde: humanização, significado e ação comunicativa. Organicom, n.16/17, p.92-108, 2012.

CESCA, Cleuza G. Organização de eventos: manual para planejamento e execução. São Paulo: Summus, 1997.

DUARTE, Jorge. Comunicação Pública. São Paulo, Atlas, 2007. Disponível em:< http://www.jforni.jor.br>. Acesso em: 14 abr.2016.

DUARTE, Jorge (Org). Comunicação Pública: estado, mercado, sociedade e interesse público. São Paulo: Editora Atlas, 2012.

FARIA, Armando M. de. Imprensa e organizações. In: DUARTE, Jorge (Org). Assessoria de Imprensa e relacionamento com a mídia. São Paulo: Atlas, 2002.p. 161-166.

FELIPPI, Ângela; BRANDT, Grazielle. Aproximações entre Estudos Culturais e Desenvolvimento Regional: uma proposta teórico-metodológica para estudar a comunicação na interdisciplinaridade. Revista Brasileira de Gestão e Desenvolvimento Regional, Taubaté, SP, v.12, n.4, p.44-63, dez.2016.

HALL, Stuart. A centralidade da cultura: notas sobre as revoluções culturais do nosso tempo. Educação \& realidade 22.2, p. 15-46, 1997. 
HALL, Stuart. Da Diáspora: identidades e mediações culturais. Belo Horizonte: Editora UFMG, 2003.

IPEA. INSTITUTO DE PESQUISA ECONÔMICA APLICADA. Políticas Sociais: acompanhamento e análise. 2015. Disponível em:< http:/ / www.ipea.gov.br/portal/index.php?option=com_content\&view=article\&i $\mathrm{d}=25812$ \&Itemid=9 $>$. Acesso em: 17 jul.2015.

JACKS, Nilda (Coord.). Meios e audiências: a emergência dos estudos de recepção no Brasil. Porto Alegre: Sulina, 2008.

LAGO, Ivann C.; ROTTA, Edmar. Sobre a relação entre cultura e desenvolvimento: alguns apontamentos em defesa do conceito antropológico de cultura. In: Anais VIII Seminário Internacional sobre Desenvolvimento Regional, 2017, Santa Cruz do Sul/RS. Santa Cruz do Sul: Edunisc, 2017. Disponível em: <https://online.unisc.br/acadnet/anais/index.php/sidr/article/view/16188>. Acesso em: 17 abr.2018.

LÓPEZ, Elaine Machado. Uma revisão do papel dos hospitais de pequeno porte no Sistema Único de Saúde (SUS). 2004, 131f. Dissertação (Programa de Mestrado Profissional da Escola Nacional de Saúde Pública da Fundação Osvaldo Cruz/Ministério da Saúde). Brasília, 2004. Disponível em:< https://www.arca.fiocruz.br/handle/icict/4864>. Acesso em 17 abr.2018.

MARTÍN-BARBERO, Jesús. Dos meios às mediações. Rio de Janeiro: UFRJ, 2003.

MONTEIRO, Graça F. A singularidade da comunicação pública. In: DUARTE, Jorge (Org). Comunicação Pública: estado, mercado, sociedade e interesse público. São Paulo: Editora Atlas, 2012. p.34-46.

SECRETARIA ESTADUAL DA SAÚDE DO RIO GRANDE DO SUL. 13 ${ }^{\mathrm{a}}$ Coordenadoria Regional de Saúde. Disponível em:< http://www.saude.rs.gov.br/lista/170/13\%C2\%AA_CRS_\%28Santa_Cruz_do_S ul\%29>. Acesso em 08 jan.2017.

ROSSIGNOLLI, C.; ASSÊENCIO, C.; CORDENONSI, A. Interesse público e critério de noticiabilidade: um estudo sobre o programa de tv Folha. In: Anais XVIII Congresso de Ciências da Comunicação na região Sudeste, 2013, Bauru, São Paulo. Disponível em:< http://portalintercom.org.br/anais/sudeste2013/resumos/R38-0617-1.pdf>. Acesso em: 14 dez.2016. 
SANT'ANNA, Francisco. Mídia das Fontes: o difusor do jornalismo corporativo. 2007. Disponível em:<http://www.bocc.ubi.pt/pag/santanna-francisco-midiafontes.pdf $>$. Acesso em: 04 out. 2016.

SANTOS, M.; SILVEIRA, M.P. O Brasil. Território e sociedade no início do século XXI. Rio de Janeiro/São Paulo, Record, 2003.

SULLIVAN, Marquerite. Uma assessoria de imprensa responsável na era digital. Bureau de Programas de Informações Internacionais - Departamento de Estado dos Estados Unidos. 2012.

WILLIAMS, Raymond. Culture is ordinary. In: GRAY, Ann; MCGUIGAN, Jim. (Org). Studyine culture. London: Arnold, 1993, p. 5-14.

ZÉMOR, Pierre. La communication publique. Puf, Col. Que sais-je? Capítulo 1: o campo da comunicação pública. Paris, 1995. Tradução resumida: Elisabeth Brandão.

<http://www.ucb.br/comsocial/mba/ComunicacaoPublicaPierreZemor_traduca o.pdf>. Acesso em: 12 dez. 2016.

ZÉMOR, Pierre. As formas da comunicação pública. In: DUARTE, Jorge (Org). Comunicação Pública: estado, mercado, sociedade e interesse público. São Paulo: Editora Atlas, 2012. p.214-245. 
Endereço para correspondência:

LidiaSchwantes Hoss - lidia@viavale.com.br Avenida Independência, 2293 - Universitário 96815-900 Santa Cruz do Sul, RS

Angela Cristina Trevisan Felippi - angelafe@unisc.br Av. Independência, 2293 - Universitário 96815900 - Santa Cruz do Sul/RS, Brasil Telefone: (51) 37177300 Ramal: 7383 